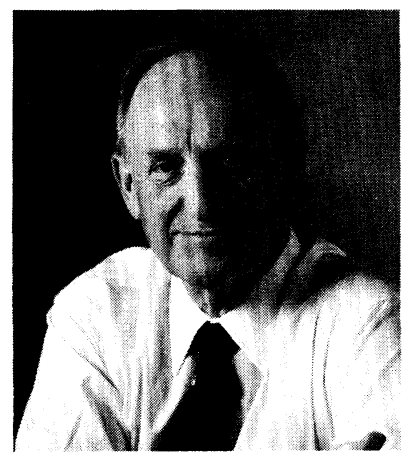

\section{Welcome Mohan; Thank You Lorretta}

It is a great pleasure for me to welcome a new member of our Optical Engineering team and to introduce him to you, our readers.

Mohan G. Nair joined the editorial and management staff of SPIE's headquarters in Bellingham toward the end of March. He is our new manager of the SPIE Journals Department and managing editor of Optical Engineering. In this new role, for him, he will be reporting directly to Eric Pepper, who is the director of publications. Many of you know Eric, and you will have a chance to meet Mohan personally at future conferences. Of course I will be working closely with Mohan and his team to continue to produce and improve Optical Engineering.

Mr. Nair brings a strong set of experiences to bear. In his own words he writes, "My background covers all aspects of book and journal publishing, including acquisition, development, and management of scientific, technical and medical publications. I have expertise in the areas of editorial/ acquisition/management, editing/design/production/manufacturing, and marketing/sales/promotion."

He received a B.A. in English from the University of Pennsylvania and an M.Phil. in English and economics from Mansfield College at Oxford University. He joins us from CRC Press where his most recent assignment was as journal manager (1989-1994).

Mohan replaced Lorretta Palagi, who has served the society with great energy, outstanding competence, and real dedication for many years. She was certainly a pleasure for me to work with and that pleasure is echoed by all the authors who have published in Optical Engineering since March of 1991. We wish Lorretta all the best in her new venture as a freelance book packager and copyeditor. She is already working with a number of major publishers to take a raw manuscript and turn it into a bound book, with all the responsibility that that process entails of editing, designing, and printing. Thank you, Lorretta, and good luck in your "go-it-alone" venture.

\section{Editor's Anecdote: It Happened in San Jose}

My wife, Joyce, and I checked into our hotel for the SPIE international symposium being held there in early February. We noticed that the message light was flashing on our telephone. I picked up the messages, including this one:

"Brian, this is Lori. I am just going down to the gift shop and will be back in my room soon."

I assumed it must be a conference-related call, and my first thought was that Lori Jenkins, a staff editor in our journals department, was at the conference and wanted to meet with me. So I dialed the hotel operator and asked to be connected to Lori Jenkins' room. The operator responded that no one by that name was registered.

It occurred to me that Lorie Pancoe, a staff member who works with our Milestone Series, must be at the meeting, so I asked that I be connected with her. The response again was "No one by that name is registered." I must say I was rather embarrassed by this time and wondered what the operator thought! I then explained my dilemma, and she very kindly looked through the list of SPIE staff who were registered and found a Lori Paulette. Still a bit mystified, I left her a return message even though I didn't recognize her name.

The mystery was solved the next morning when I met Lori Paulette, who works in the SPIE Membership and Administrative Services Department. She thought she was leaving a message for Brian Thomas, SPIE's manager of New Media Development, because they had a meeting that evening!

Of course I promised not to tell the story to anyonewell, maybe a few close friends.

Brian J. Thompson Editor 
June 1995

Polarization Analysis and Measurement Dennis H. Goldstein WL/MNGA

101 West Eglin Boulevard, Suite 280 Eglin AFB, FL 32542

904/882-4636 ext. $2399 \cdot 904 / 882-4034$ FAX

E-mail: goldstei@eglin.af.mil

David B. Chenault

Naval Research Laboratory

Code 5622, Optical Sciences

4555 Overlook Avenue

Washington, DC 20375-9998

202/767-0390 • 202/767-6370 FAX

E-mail: chenault@nrlfs1.nrl.navy.mil

Russell A. Chipman

University of Alabama in Huntsville

Physics Department, Optics Building 318

Huntsville, AL 35899

205/895-6417 ext. $318 \cdot 205 / 895-6873$ FAX

E-mail: chipmanr@email.uah.edu

\section{July 1995}

Optics in Switzerland, Part 1: Federal Institutes of Technologies

P. K. Rastogi

Swiss Federal Institute of Technology-Lausanne

Laboratory of Stress Analysis

CH-1015 Lausanne

Switzerland

E-mail: rastogi@elgc.epfl.ch

(021) $6932445 \cdot$ • (021) 6934748 FAX

August 1995

Photorefractive Nonlinear Optics

Partha P. Banerjee

University of Alabama in Huntsville

Department of Electrical and Computer

Engineering

Huntsville, AL 35899

205/895-6215 ext. $416 \cdot 205 / 895-6880$ FAX

Optics in Switzerland, Part 2: Universities and Research Institutes

P. K. Rastogi

Swiss Federal Institute of Technology-Lausanne

Laboratory of Stress Analysis

CH-1015 Lausanne

Switzerland

E-mail: rastogi@elgc.epfl.ch

(021) 6932445 • (021) 6934748 FAX

\section{September 1995}

Optical Science and Engineering in Finland

Seppo Honkanen

Nokia Research Center

P.O. Box 45

FIN-00211 Helsinki

Finland

+35804376471・+35804552557 FAX
Optics in Switzerland, Part 3: Industries and Observatories

P. K. Rastogi

Swiss Federal Institute of Technology-Lausanne Laboratory of Stress Analysis

CH-1015 Lausanne

Switzerland

E-mail: rastogi@elgc.epfl.ch

(021) $6932445 \cdot(021) 6934748$ FAX

\section{November 1995}

Optical Remote Sensing and Image

\section{Processing}

Mohammad A. Karim

Bradley D. Duncan

University of Dayton

Center for Electro-Optics

300 College Park

Dayton, OH 45469-0227

$513 / 229-2241 \cdot 513 / 229-3177$

513/229-2471 FAX

\section{December 1995}

Optics in Polymer Science and Technology

Maksymilian Pluta

Institute of Applied Optics

Kamionkowska 18

03-805 Warsaw, Poland

(4822) $184405 \cdot$ (4822) 133265 FAX

Andrzej Wasiak

Institute of Fundamental Technological Research Polish Academy of Sciences

Savietokrzyska 21

00-012 Warsaw, Poland

(4822) 269815 FAX

\section{January 1996}

Optical Science and Engineering in Argentina

Guillermo H. Kaufmann

Universidad Nacional de Rosario

Instituto de Fisica Rosario

Applied Optics Group

Bv. 27 de Febrero 210 bis

2000 Rosario

Argentina

E-mail: guille@ifir.edu.ar

or gkaufman@arosario.bitnet

5441825838 • 5441257164 FAX

Visual Communications and Image Processing

Cheng-Tie Chen

Bellcore, NVC 3X-321

331 Newman Springs Road

Red Bank, NJ 07701

908/758-3106 • 908/758-4371 FAX

E-mail: ctc@nyquist.bellcore.com
Kou-Hu Tzou

COMSAT Laboratories

22300 Comsat Drive

Clarksburg, MD 20871

301/428-4663 • 301/428-9287 FAX

E-mail: kouhu@ctd.comsat.com

Ya-Qin Zhang

GTE Laboratories

40 Sylvan Road

Waltham, MA 02254

617/466-2259 • 617/890-9320 FAX

E-mail: yz00@gte.com

February 1996

Optical Engineering in Small Companies

Xiangyang Yang

University of New Orleans

Department of Electrical Engineering

New Orleans, LA 70148

504/286-5524 • 504/286-3950

E-mail: xxy@uno.edu

William J. Miceli

Office of Naval Research

800 North Quincy Street

Arlington, VA 22217-5000

703/696-5752 • 703/696-1330 FAX

Manuscripts due July 1, 1995

March 1996

Sensor Fusion

Belur V. Dasarathy

Dynetics, Inc.

P.O. Box Drawer B

Huntsville, AL 35814-5050

$205 / 922-9230$ ext. $355 \cdot 205 / 922-9219$ or

205/922-9260 FAX

E-mail: belur@dynetics.com

Manuscripts due Aug. 1, 1995

April 1996

\section{Optical Security}

Joseph L. Horner

Rome Laboratory

Department of the Air Force

Hanscom AFB, MA 01731

617/377-3841 • 617/377-2836 FAX

E-mail: horner@eastlouex.rl.af.mil

Bahram Javidi

University of Connecticut

Electrical and Systems Engineering Department

U-157, Room 312, Eng. III

260 Glenbrook Road

Storrs, CT 06269

203/486-2867 • 203/486-0318 FAX

E-mail: bahram @eng2.uconn.edu

Manuscripts due Sept. 1, 1995 